Article

\title{
Dialectical Design Dialogues: Negotiating Ethics in Participatory Planning by Building a Critical Design Atlas
}

\author{
Barbara Roosen ${ }^{1}$, Liesbeth Huybrechts ${ }^{1}$, Oswald Devisch ${ }^{1}$ and Pieter Van den Broeck ${ }^{2, *}$ \\ ${ }^{1}$ Faculty of Architecture and Arts, University of Hasselt, 3590 Diepenbeek, Belgium; \\ E-Mails: barbara.roosen@uhasselt.be (B.R.), liesbeth.huybrechts@uhasselt.be (L.H.), oswald.devisch@uhasselt.be (O.D.) \\ 2 Department of Architecture, KU Leuven, 3000 Leuven, Belgium; E-Mail: pieter.vandenbroeck@kuleuven.be \\ * Corresponding author
}

Submitted: 29 May 2020 | Accepted: 28 August 2020 | Published: 12 November 2020

\begin{abstract}
This article explores 'dialectical design dialogues' as an approach to engage with ethics in everyday urban planning contexts. It starts from Paulo Freire's pedagogical view (1970/2017), in which dialogues imply the establishment of a horizontal relation between professionals and amateurs, in order to understand, question and imagine things in everyday reality, in this case, urban transformations, applied to participatory planning and enriched through David Harvey's (2000, 2009) dialectical approach. A dialectical approach to design dialogues acknowledges and renegotiates contrasts and convergences of ethical concerns specific to the reality of concrete daily life, rather than artificially presenting daily life as made of consensus or homogeneity. The article analyses an atlas as a tool to facilitate dialectical design dialogues in a case study of a low-density residential neighbourhood in the city of Genk, Belgium. It sees the production of the atlas as a collective endeavour during which planners, authorities and citizens reflect on possible futures starting from a confrontation of competing uses and perspectives of neighbourhood spaces. The article contributes to the state-of-the-art in participatory urban planning in two ways: (1) by reframing the theoretical discussion on ethics by arguing that not only the verbal discourses around designerly atlas techniques but also the techniques themselves can support urban planners in dealing more consciously with ethics (accountability, morality and authorship) throughout urban planning processes, (2) by offering a concrete practice-based example of producing an atlas that supports the participatory articulation and negotiation of dialectical inquiry of ethics through dialogues in a 'real-time' urban planning process.
\end{abstract}

\section{Keywords}

atlas; dialectics; dialogues; ethics; mapping; neighbourhoods; participatory urban planning

\section{Issue}

This article is part of the issue "Built Environment, Ethics and Everyday Life" edited by Mattias Kärrholm (Lund University, Sweden) and Sandra Kopljar (Lund University, Sweden).

(C) 2020 by the authors; licensee Cogitatio (Lisbon, Portugal). This article is licensed under a Creative Commons Attribution 4.0 International License (CC BY).

\section{The Ethics of Participatory Urban Planning}

This article explores an approach to articulate and deal with ethical questioning in participatory urban planning practice and builds upon insights from participatory design, urban planning and mapping theory. It starts with the belief that the unpredictable nature of participatory urban planning processes requires an open approach that can deal with ethics 'in real-time' (Kelly, 2018) during the process.
Such an approach challenges the working relations among designers and planners by abolishing a single professional perspective to ethics in planning and making a shift to multiple, situated perspectives to ethics that are shaped through on-going processes of debate. When all actors are considered equally during the participatory process, (moral) responsibilities and ownership of design proposals are also being questioned. As such, as feminist scholars Barad (2007) and Suchman (2002) also demonstrate in their writings, questions of morality, authorship 
and accountability become part and parcel of the negotiation process. Several authors in participatory design today suggest considering every meeting of human and non-human actors in a design process as an ethical encounter which needs to go hand in hand with recognising and negotiating the specific responsibilities that come with the role humans and non-humans have in a particular relation (e.g., Spiel, Brulé, Frauenberger, Bailley, \& Fitzpatrick, 2020).

This article discusses an approach capable of dealing with these questions around morality, authorship and accountability in real-time throughout urban planning processes. It explores a concrete case study in which researchers-planners engaged in a low-profile planning context in the city of Genk, Belgium and co-produced an atlas as a participatory planning and design tool to address ethical questions throughout the process. Based upon this research experience, the article aims to contribute to the theoretical discussion on how to relate in real-time to ethical questions in participatory planning processes, as well as to gain insights for planning practice on the use of an atlas in situations where ethical questions impose themselves. To frame the case study elaborated in section two, the next sections first explore the key concepts of dialogues, dialectics and the atlas.

\subsection{Dialogues}

The growing focus on spatial planning for everyday life experience and how it is shaped by various dimensions of society brought about a necessary shift towards more collaborative planning practices (Healey, 1997). In this process, the dialogue became an important ingredient of planning practice to deal with the complexity and diversity of interests of actors in spatial transformation processes. However, when discussing the ethics of participatory planning processes, we need to pay close attention to how these dialogues are shaped. In order to consciously shape these dialogues while paying close attention to ethics, we found inspiration in Freire's (1970/2017) pedagogical view on dialogues. Starting from Marxist thinking, he defines dialogues as an emancipatory and creative act to enact transformations in a reciprocal relationship between teacher and student. When translated to the planning context, dialogues can be seen as conversations that can be steered by everyone in the process, within horizontal relations among all stakeholders based upon mutual respect and trust in which each member acknowledges and engages with the other (Freire, 1970/2017; Rule, 2011).

Freire's approach teaches us that dialogues can enable planning processes to become processes of horizontal and mutual learning. In his view, perceptions and experiences are shaped by everyday praxis and spaces. As such, the dialogues that planners enter into need to tap into concrete and recognizable situations by shaping a learning relationship with the people who inhabit, organise or maintain these spaces. This could trigger col- lective manoeuvre room for new thoughts, design, and new practices to emerge. Freire's work lies at the basis of many recent reflections on the role of dialogues in shaping the politics of participatory design and planning processes (Salazar, Zuljevic, \& Huybrechts, 2018; Serpa, Portele, Costard, \& Silva, 2020). In previous research, we aimed to enrich the knowledge of the particular qualities of these dialogues in a participatory urban planning context. By making an overview of different types of dialogues (and media) that occurred in two urban planning cases, we discovered differences in how designerly dialogues can build capacity among the actors involved, to explore, reflect, design and act together upon sociospatial challenges. It became clear that too often the political role of design tools in entering and shaping a political space through dialogues, where roles are shifted and capabilities are built, is underestimated (Huybrechts, Dreessen, \& Hagenaars, 2018; Huybrechts, Dreessen, Schepers, \& Calderon Salazar, 2016; Huybrechts, Roosen, Verbakel, \& Schreurs, 2019; Huybrechts, Teli, Zuljevic, \& Bettega, 2020). In line with this research, in this article, we study more profoundly this political role of design tools and techniques to facilitate dialogues within participatory planning processes. More specifically, we aim to explore how planners can engage with the ethical questions that such dialogues generate, summarised earlier as questions of morality, authorship and accountability.

\subsection{Dialectics}

However, not all dialogues provide space for politics and ethical questioning. In current theoretical discussions on participatory planning, it has been argued that the focus on consensus in dialogues erases ethical questions. Indeed, the focus on consensus has been criticised for not being able to critically question existing power relations and avoiding the renegotiation of the position of dominant actors who suppress certain positions. In these theoretical approaches there is a call for more agonistic, adaptive and discursive perspectives to planning that focus on conflictuality, unequal power relations and uncertainty inherent to spatial transformation processes (Hillier, 2007, 2011; Metzger, Allmendinger, \& Oosterlynck, 2014; Mostafavi, 2017; Swyngedouw, 2005; Van den Broeck, 2019). Many of these theories build upon the Marxist dialectical tradition that offers a critical and bottom-upward approach to incorporate complexity and multiple perspectives in urban transformation processes, seeking connection between reflection and action, particularities and generalities. This tradition pays close attention to uneven power relations across different scales and dimensions and to the emancipatory meaning of these processes to shed light on everyone's right to intervene in spatial transformation processes (Merrifield, 2002).

Therefore, the concept of 'dialectics' is productive for planners who want to articulate ethics in the dialogues they enter into, because it seeks generative tensions, 
contrasts and contradictions embedded in the everyday which uncover latent opportunities to develop capabilities among designers, planners, inhabitants and policymakers to understand and generate accountability to intervene in our living environment (Harvey, 2000, 2009; Loftus, 2012). Harvey (2009) focuses upon dialectical relations between (1) everyday life, (2) the kind of perceptions and ideas, (3) we build in relation to social ties between individuals, groups and institutions, (4) nature, (5) technology and (6) modes of production and labour. Only when conscious about contradictions and continuities between those six moments, can we "fight conceptually and intellectually over alternatives" (Harvey, 2009, p. 237). In this sense, when urban planning projects shape the dialogical exchange in a dialectical way, the negotiations between diverse types of knowledge and practices within these different moments become apparent as important moral choices. To further investigate the real-time ethical questioning in participatory urban planning processes, we, therefore, foreground the concept of 'dialectical design dialogues' which we define as mutual learning processes that initiate, continue and shift dialogues to reveal and acknowledge, articulate and negotiate dialectics between different ethical concerns in participatory planning, starting from concrete and recognizable situations in everyday life realities.

\subsection{The Atlas}

How can we now use the concepts of dialogue and dialectics to enable debates and practices around ethical questions that emerge during participatory planning processes? How can urban designers, researchers or planners create space for complexity, conflicts and dissenting opinions? In this article, we study dialectical design dialogues through urban planning practice via the atlas, a tool proper to the research and design language of planners. An atlas is basically a collection of maps, in which each map relates to other maps and as such becomes part of a broader and more complex story. By representing and describing the same space in multiple ways, an atlas is able "to approximate the rich complexity of a place" (Solnit, 2010, p. 1). Seeking confrontation and the interplay of maps enables atlas makers to create novel stories through critical investigation of well-established, often predefined atlas and mapping techniques (Cattoor \& Perkins, 2014; Wood, 1987). This critical investigation is necessary for creating space for dialectical design dialogues, because, as Söderström (1996) points out, default mapping conventions tend to impede novel ways of reading, designing and managing the urban territory.

There are many different ways in which mapping can demonstrate tensions (Crampton \& Krygier, 2006) and reveal ethical questions concerning urban transformation processes. In participatory planning practice, on the one hand, participatory and community mappings provide a political tool to open up urban planning to amateurs (Parker, 2006) in search of inclusion (of social and cul- tural groups and societal themes to avoid elite mapping productions), transparency (about goals, context and authorship in order to keep mapping accountable) and empowerment (of multiple actors involved to inform and inspire collective actions). On the other hand, there are designerly and analytical mappings "in which expert spatial knowledge operates" (Cattoor \& Perkins, 2014, p. 167) with the ambition to "discover new worlds within the past and present ones; they inaugurate new grounds upon the hidden traces of a living context and actualize those potentials" (Corner, 1999, p. 214). Each of those two types of mapping set relationships between specific perspectives and agendas and as such create space to reveal dialectics between them. However, dialogues about tensions and relationships between these two different types of mapping and the knowledge that they produce in planning processes appear to be difficult and therefore particularly important to address. Therefore, this article particularly aims to further investigate the use of the atlas as a critical method of confronting maps, perspectives and knowledge, but then as a participatory and coauthored planning tool to negotiate ethical concerns together. Therefore, the article foregrounds the following question: What is the role of an atlas as a tool in unveiling the dialectics between and through different mappings in planning processes, enabling dialogue on ethical concerns that emerge from collecting, confronting and working with different forms of knowledge and involving both professionals and citizens?

To investigate this question, this article describes a case study of a low-density residential neighbourhood, Oud-Waterschei, in the former mining city of Genk, Belgium. We experimented with an atlas to facilitate dialectical design dialogues in order to engage with different agendas, claims, issues, viewpoints and ethical concerns triggered by future transformations of the neighbourhood. The article describes and discusses how we experimented with atlas and mapping techniques. In the next section, we will first talk about the specific planning context of the residential neighbourhood we worked in and then focus on one specific dialectical design dialogue to analyse how the unveiling of dialectics in the atlas helped to negotiate conflicting ethical concerns.

\section{Dialogues in a Residential Neighbourhood}

\subsection{Case Study Context}

The city of Genk originates from a grid of cités (neighbourhoods planned in line with the garden city model) and mining sites, imposed upon the landscape of agrarian hamlets in the marshy and fertile valley of the Stiemer creek in the beginning of the 20th century (Nolf, 2013), attracting Italian, Turkish and Polish immigrants to work for the coal mining companies. Its particular development resulted in a fragmented city with multiple cultural communities and a rather low population density of 755 inhabitants per $\mathrm{km} 2$. The district 
of Oud-Waterschei, with a population density of only 429 inhabitants per km2, originates from one of the original hamlets and is separated from the former mining site and cité of Waterschei by a wide avenue and the Stiemer creek. After WWII, Oud-Waterschei urbanized in the form of plot-by-plot development of single-family detached houses, gradually taking in woods and pastures along its agricultural roads. Large perimeter low-density blocks emerged, subdivided into deep parcels leaving room for vegetable gardens, workhouses and internal wooded areas. Between 2017 and 2019 the research team engaged with the neighbourhood within the framework of academic research, a public assignment and an educational program that were mutually aligned: (1) The academic PhD research of the first author looks into the role of an atlas in revealing and debating the socio-spatial complexity of low-density residential neighbourhoods; (2) the three-year public assignment RoadWorks, commissioned by the city of Genk, aimed to develop a vision and policy recommendations for its soft connection network. The first two authors were part of the design team in collaboration with the NGO Trage Wegen (Soft Connections) and LUCA School of Arts; and (3) the urban design seminar organised by the three first authors during fall 2018, engaged seven Master in Architecture students in designerly research through dialogues and mapping with local actors in Oud-Waterschei.

All three processes were organized as a series of 'dialogical' activities. These included bilateral conversations with different departments of the city administration and the design team of RoadWorks, individual talks with passers-by, in-depth talks with key actors or co-design sessions with a mix of inhabitants, civil servants, ONGs, planners and architecture students. In all, around 50 dialogical activities were organized by three researchers and three students, involving around 50 inhabitants, 15 civil servants, 10 ONGs and 10 spatial professionals.

In each of these dialogical activities, the main researcher brought hard copies of parts of the atlas. These could both include maps summarizing previous activities or existing maps of the area, such as printouts of various analytical and policy maps (some of them produced digitally by the researchers). Both the researchers and students brought their own maps based on approximatelyfor each student-10 individual talks with passers-by of different ages and cultural backgrounds on location to assemble diverse perspectives and opinions on the role of soft connections in this low-density neighbourhood. These conversations started from concrete tensions (for example a path that would soon disappear) indicated on a map to which comments were manually added.

Most of the activities were held and documented live via a large paper-based neighbourhood map $(2 \mathrm{~m} \times 2 \mathrm{~m})$, the main material of the atlas, accompanied with other printed visual material (produced digitally by the researchers). On this neighbourhood map, the researchers discussed the dialogues between the maps in four meetings of the steering group of the RoadsWorks project, during five in-depth dialogue sessions with key actors during the urban design seminar. In 11 co-design sessions held in the neighbourhood, we invited 3-5 participants. The choice of participants and topics was proposed by the researchers themselves, the city administration, and also by inhabitants at earlier activities.

In each of the activities, in-depth engagement with a small number of participants was preferred over superficial engagements with large numbers of people. Along the same line of thinking, we chose in this article not to present general fieldwork findings, but rather a detailed account of a particular dialectical design dialogue.

\subsection{Dialectical Design Dialogue Triggered by an Atlas}

One of our dialogues focussed on the Mispad grove, a soft connection enclosed by housing ribbons and one of the last remnants of the Stiemer creek landscape in Oud-Waterschei. The municipal project leader of the RoadWorks project disagreed with our focus and worried that it would disturb the realisation of the master plan which involved around sixty new houses in the Mispad grove, a project which was contested by surrounding homeowners because they would lose part of their private back gardens. The municipality's reaction revealed a socio-economic dialectic at play, but also an 'internal' inconsistency between the municipal housing plan and the municipal ambition to reinforce the creek valley landscape in the city. The researchers and project leader agreed to shift the focus of the neighbourhood dialogue to the adjacent enclosed Brentjes grove.

During a series of site visits to Brentjes grove, passersby of various socio-cultural backgrounds described the grove as a forgotten space where they or their children played before but where now nature had taken over. The announcement of the construction of a new house meant that the remaining access to the area, across a private plot, would disappear. We decided to label this plot 'passage plot' and put it on a large 'neighbourhood map' (see Figure 1). Together with the maps showing the dialectics around the Mispad grove, this was the starting point of our first co-design session which we hoped would trigger critical reflection about individual property and building rights vis-à-vis common needs such as space for recreation, soft mobility, nature, biodiversity and water.

During the first co-design session, participants started, each from their own practice and experience, imagining tools and actions that might address these dialectics. A planning official started to consider technical possibilities to protect accessibility at strategic places including conditions of 'right of way' in building permits. The neighbourhood manager launched the idea to shed more light on the discussion, organising the annual neighbourhood walk across these forgotten groves. The researchers labelled this idea in the atlas the 'do-ityourself path.' The director of the local school made the link to the school's location, also a site enclosed by hous- 


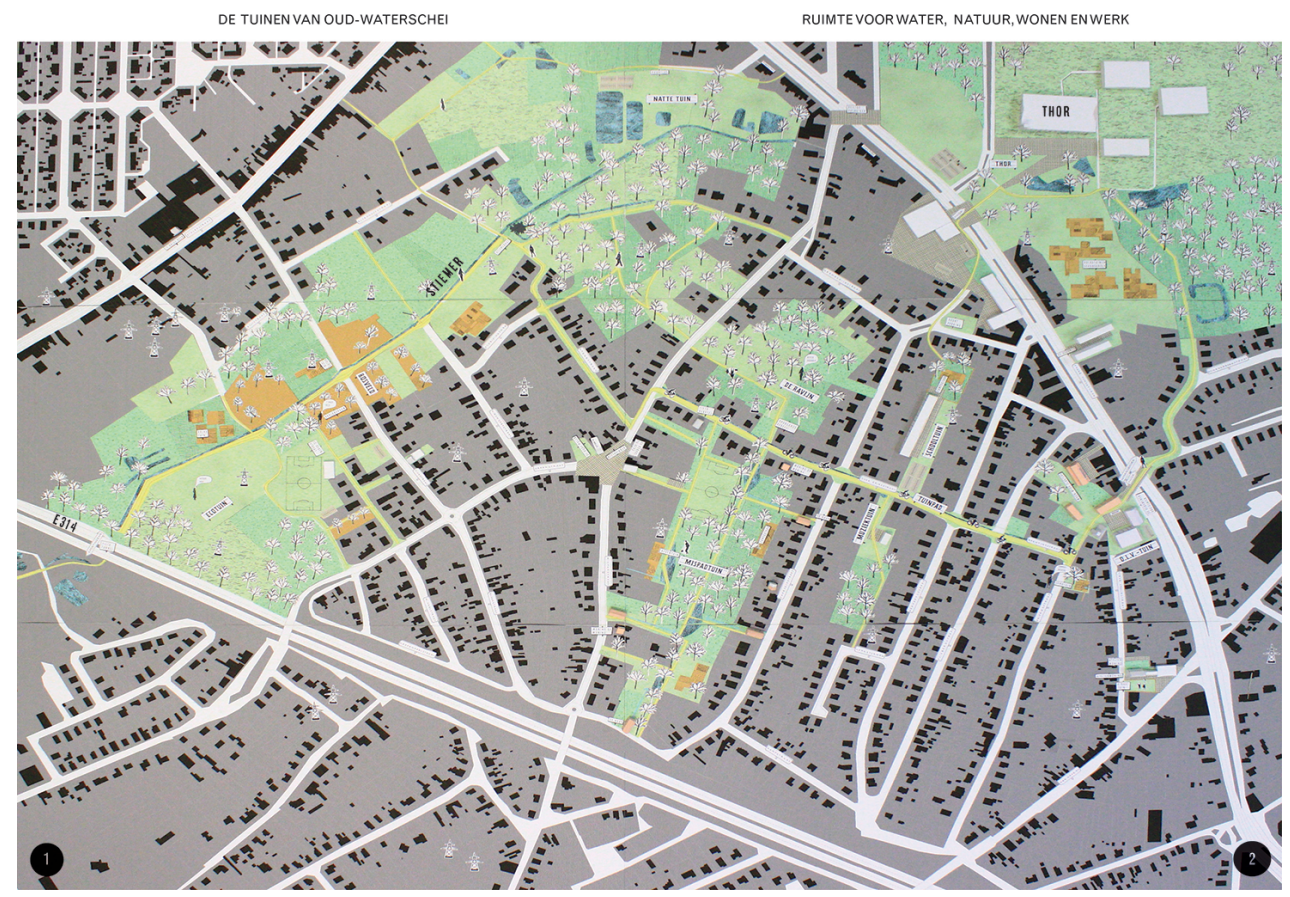

Figure 1. The neighbourhood map on a double page in the first section 'places' of the atlas. Source: Anse Arits, Laura Enkels, Julie Polus, Alexander Verlaak, and Barbara Roosen (based on the digital topographic map of Flanders, GRB 2018).

ing plots. He imagined a second pedestrian access to the school as a means to address its current mobility and parking issues. During these dialogues, more neighbourhood spaces were visualised on the neighbourhood map (including groves, bare land and public services such as the school), and links to other key actors, such as the municipal 'compost master,' were made (see Figure 2). In a later phase, a local organic farmer got involved as well, in search of fertile land in the city for extensive agro-forestry. We documented all inputs in the atlas and decided to label all open spaces as 'collective neighbourhood gardens.'

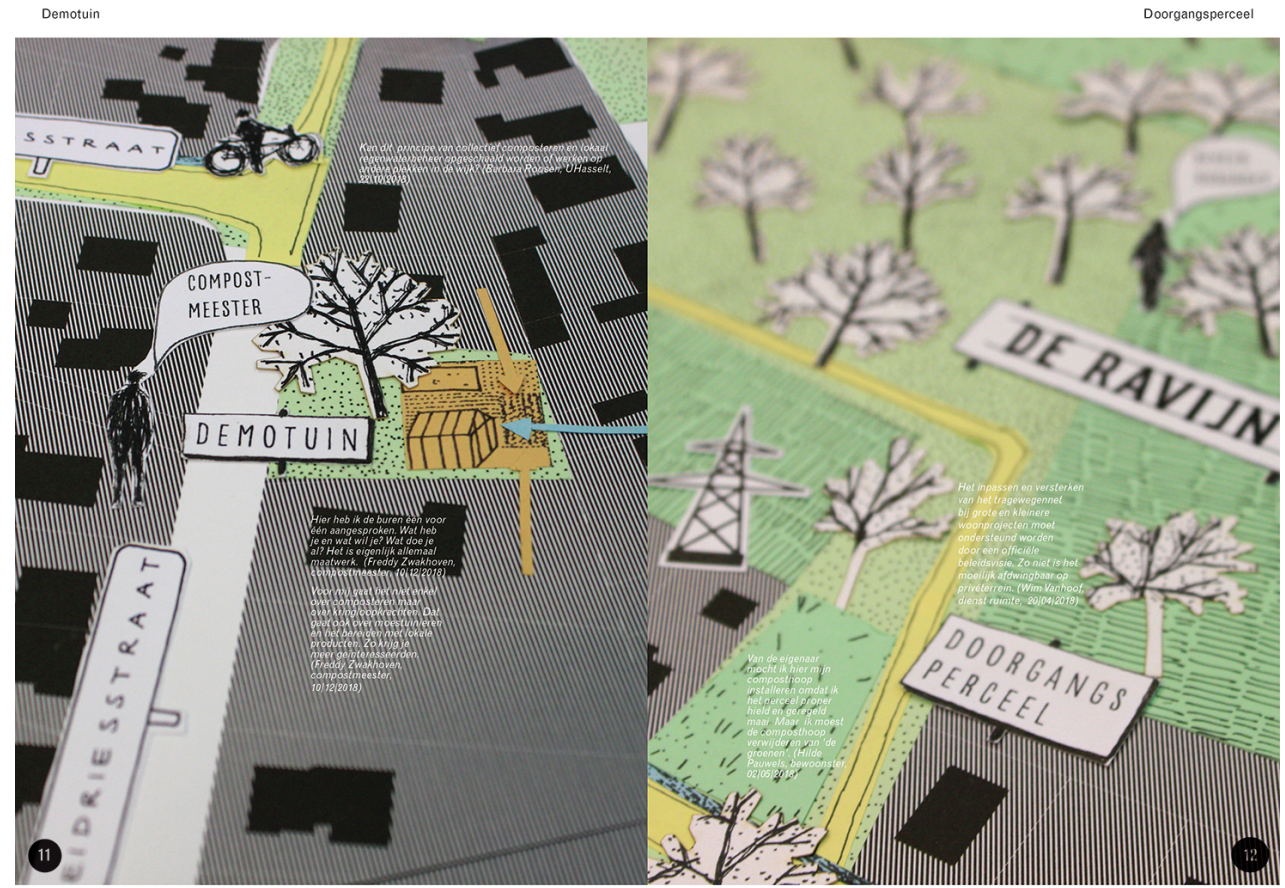

Figure 2. Double page from the atlas' first section 'places' with the 'neighbour compost network' and the 'passage plot.' Source: Anse Arits, Laura Enkels, Julie Polus, Alexander Verlaak, and Barbara Roosen (based on the digital topographic map of Flanders, GRB 2018). 
During the second co-design session, the compost master together with two inhabitants and the neighbourhood priest reflected together on our labels and explored the idea of a 'compost school' as an extension of the existing compost network of the compost master. At the same time, the priest pointed at a new dialectic: Many neighbourhood gardens contain social facilities, but most of them are underused and neglected because policy focuses on more central locations in the city. In order to negotiate this dialectic in greater depth, we decided to make a map showing the state and occupancy rate of all the neighbourhood facilities.

We decided to present our atlas to the design team of the master plan of the Stiemer creek. The 'collective neighbourhood gardens' of Mispad and Brentjes triggered their interest as potential systems for local rainwater re-use and infiltration in the form of sustainable urban drainage solutions, wadis and rain gardens. To explore these latent possibilities with residents and local policymakers, we decided to visualize these systems in the atlas.

This became the starting point to re-initiate the dialogue about the Mispad garden, shifting focus from conflicting individual concerns of the municipality and property owners towards broader common concerns such as rainwater infiltration. To support these common concerns, the students explored alternative densification strategies based on existing housing practices in the neighbourhood, proposing a densification of the existing built-up parcels, as such minimizing extra mineralisation and maximizing rainwater infiltration. During the following co-design sessions, we learned that inhabitants were not so much concerned about these sustainability issues, but were interested in the affordable, collective and flexible housing models of the students as these would allow them to keep on living in their neighbourhood.

The above fragment of the dialectic design dialogues illustrates the horizontal and unpredictable character of the process where design choices both emanate from conversations between actors, practices and projects. Some of the dialogues only lasted as long as the dialogical activities, whereas others continued, working towards concrete projects, such as the compost school garden and the concept of passage plots that were both included in the municipal policy plan concerning soft mobility.

\section{Shaping Dialectical Design Dialogues on Ethics through Atlas Techniques}

Our atlas not only triggered dialogues that allowed for more dialectical interactions including opposition, discussions, conflict, and (partial) consensus building but also helped to address ethical concerns including morality, authorship and accountability. We will discuss how atlas techniques such as structuring, selecting, labelling, montage and referencing allowed us to collect, confront and work with different forms of knowledge and, as such, enabled the real-time making of ethical choices in dialogical, careful and conscious ways. Figure 3 illustrates how we designed atlas techniques to raise ethical concerns in the dialogue fragments analysed in Section 2.2 and how these helped unveiling dialectics which articulated ethical questions as part of the conversations. In what follows, we discuss five examples of how we used atlas techniques to steer our dialectical design dialogue in Oud-Waterschei.

\subsection{Structuring the Atlas to Anticipate Dialogues}

At the start of the process, we structured the atlas into two sections: 'places' and 'perspectives.' The first section 'places' consisted of a large neighbourhood map (see Figure 1). This map was used during all the co-design sessions and in-depth talks in order to collect stories about meaningful collective spaces of the past, present and future. The map visualized the neighbourhood's private built environment (in black underlay) concerning its collectively used spaces (in coloured paper), based upon the principle of the Nolli map to highlight spaces of collective use (Tice \& Steiner, n.d.). Each of the stories on neighbourhood spaces discussed was documented in the atlas on a card with a title and explanatory text made by the researchers or students. The second section 'perspectives' assembled both existing maps of Oud-Waterschei and digital maps produced by the researchers or students: expert maps, policy maps, observational mappings and data visualisations.

When the first two sections gained body and depth, and participants started to imagine possible (design) actions, the researchers anticipated and added a third and fourth section: 'policy' and 'tools for action.' The third section aimed at presenting the institutional context, questioning potential synergies and conflicts between on-going policy processes and concrete collective neighbourhood spaces. Both the Stiemer creek master plan and a neighbourhood mobility plan in development were part of this section. The fourth and last section was aimed at collecting concrete 'tools for action,' which were introduced during the dialogue actions. Acknowledging that transformations require multiple pathways, both bottom-up and top-down, we considered a wide set of tools: Institutional, legal, technical, activist and design tools to claim space, raise awareness about particular spaces, to connect, organise or manage them in other ways. For example, 'the right of way' was categorized as a tool to claim space.

In hindsight, structuring the atlas into these four sections turned out to be a pragmatic translation of Harvey's 'method of moments' (2009) with which he argues that durable transformations require moments that relate everyday life with other fields such as technology, nature, modes of production, social relations and ideas from everyone involved. This is exactly what our atlas does: our first section focuses on everyday life experiences and was then confronted with the second section of maps, data vi- 


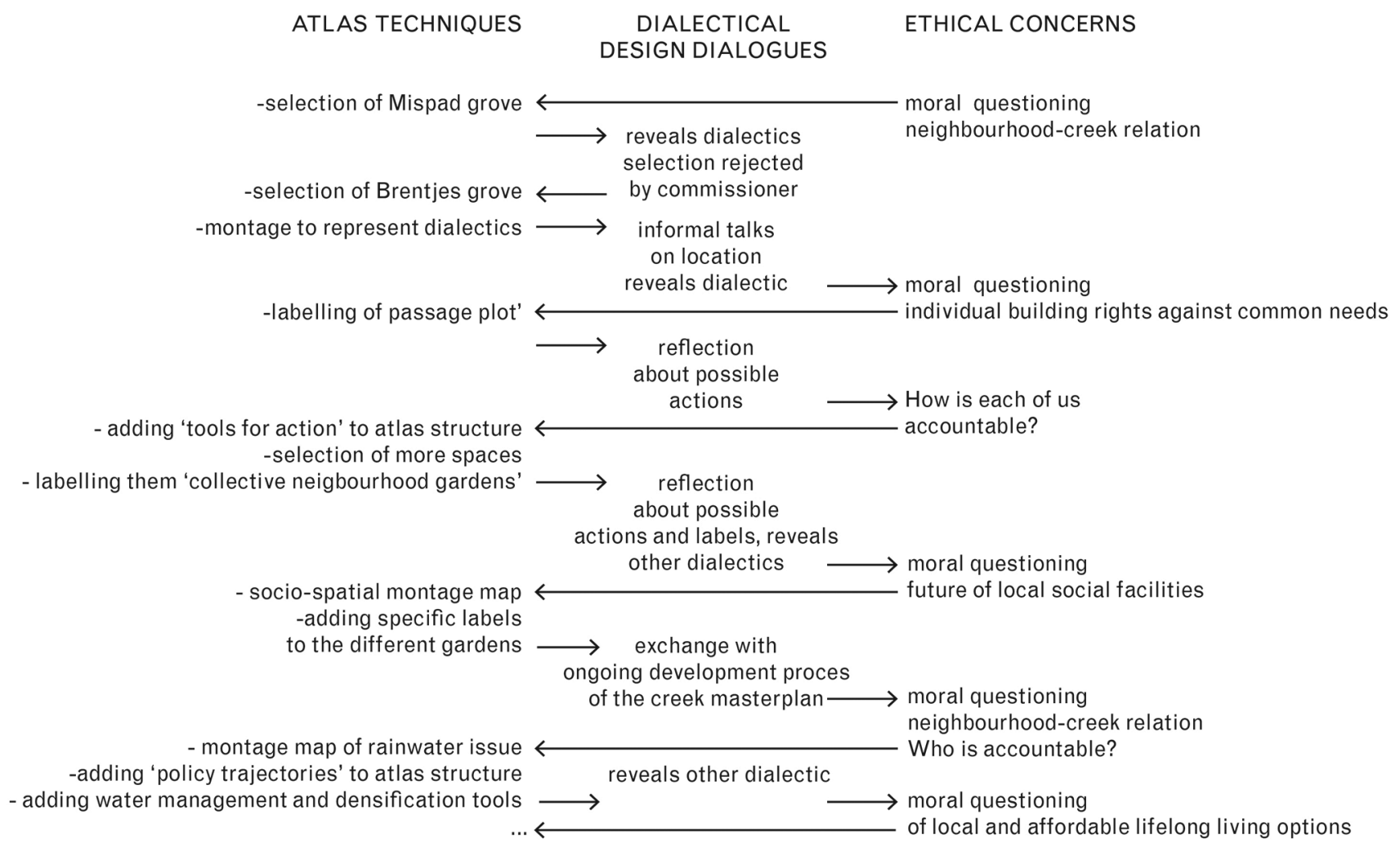

Figure 3. Interplay between atlas techniques and ethical questions within dialectical design dialogues. Source: Barbara Roosen.

sualisations, etc., generating dialectics with other ideas and perspectives. Realizing that transformation cannot derive from bottom-up and citizen-led actions alone, we introduced a third section to include dialogues with municipal and regional policy. Acknowledging the need to engage with multiple actions, we discussed a wide range of tools in Section 4 that might contribute to fundamental socio-environmental transformation.

\subsection{Montage to Reveal (Hidden) Dialectics Together}

The large neighbourhood map, part of the first section, was conceived as a 'montage' of physical and social dimensions: Coloured textures were used to detail material aspects (surfaces, buildings, plants, furniture, infrastructures, borders, water); printed figures were used to represent key actors and a set of labels was used to mention particular names or functions. Working with removable paper layers opened the map-making to all participants (both professionals and amateurs). For example, when the students imagined agro-forestry along the creek, the local organic farmer argued that the levelling of that specific terrain would obstruct organic agricultural use. He removed the patch of agricultural land and started a dialogue on alternative locations.

In the second section of the atlas, we started playing with the 'montage' of different maps and images in order to unveil (hidden) dialectics. For example, the map of the sewerage system (having overspill in the creek) was placed next to the map of the built-up and sealed surface in the neighbourhood, making the effect of sealed surface and housing upon the problematic local rainwater management more tangible (see Figure 4). This montage enabled both residents and civil servants to reflect upon alternative densification strategies at the edges of the Mispad garden.

\subsection{Selecting (in) Dialogue}

The decision to include a map in the atlas is never neutral and always entails a strategic and moral choice. With our selection of maps, we wanted to break down existing dichotomies between the valley landscape and the built environment of the neighbourhood and we wanted to make the diversity of interests visible. For instance, by carefully representing perspectives of groups that were reached in informal talks but that were difficult to involve during the co-design sessions (e.g., inhabitants of Turkish background discussing affordable housing) on the neighbourhood map, we were able to make these perspectives part of the design dialogues.

In the steering group and co-design sessions, participants discussed selections more directly to integrate and place their agendas in dialectical relations, or re-direct future dialogues. While in the beginning, selections were made to collect a large diversity of everyday knowledge, during the process we decided to also confront this situated subjective knowledge with additional selected 'ob- 


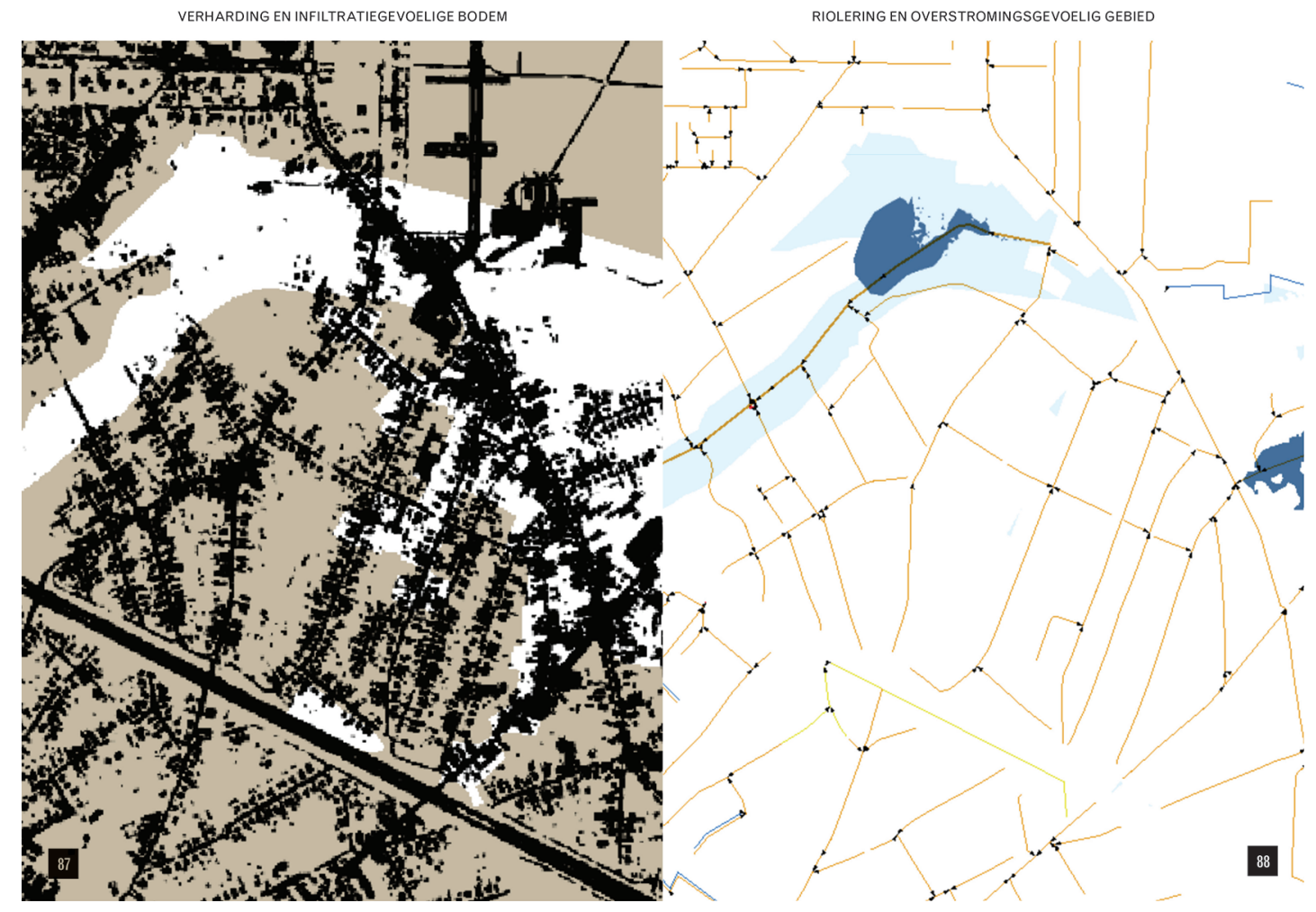

Figure 4. Double page from the second section 'perspectives' of the atlas showing the neighbourhood's sewerage system (orange) and flood zones (blue) on the right against the neighbourhood's mineralized surface (black) and soil suitable for infiltration (brown) on the left. Source: Anse Arits (based on the watertoets [water check] 2017 and sewerage database of Flanders 2018 [right map] and BAK 2015 [soil cover map of Flanders; left map]).

jective' data and professional expertise that was found for example in dialogue with the design professionals of the master plan of the Stiemer.

\subsection{Labelling to Question, Reframe and Rethink}

The participatory labelling of places, actors and tools generated a growing (critical) design vocabulary about neighbourhood spaces, both in local and in professional terms. This enabled the participants to collaboratively question the used words and visual signs and their meaning and at the same time resulted in a shared language that can support the exchange of knowledge and expertise between different actors involved. The labels were used to express the socio-spatial particularities of past, existing or imagined collective places, revealing their collective use and meaning. Labelling a private vacant plot as a 'passage plot' provides a good example, showing how it made the abstraction of the specific place, enabling the imagination of its possibilities in other locations. Another example, by identifying enclosed groves and bare land as gardens, we started to rethink and rework them into spaces of collective value. In line with Freire's (1970/2017) horizontal and transformative idea of dialogues, specifying each garden's name became a collective design act through which the garden's future on the neighbourhood map could be negotiated. As such, the 'Ravijn' (the canyon) was chosen to label the Brentjes grove. The place was known as such by inhabitants, referring to its rough terrain. Formalising the name on the neighbourhood map highlighted its ecological claim by inhabitants.

\subsection{Referencing to Render Authorship More Transparent}

After several dialogical actions, we started to notice that the multiple relations between the four sections of our atlas-places, perspectives, policies and tools-became very complex at the cost of clarity. During conversations with people who were not involved in the process, it was revealed that the relations between different sections were not always clear to them. Moreover, we noticed that co-authorship of the selection, labelling and mounting of the material was not transparent to outsiders. In response, we introduced a detailed referencing system that worked in two ways. First, we started to clearly document the origin and authorship of all the material (when and by whom it had become the subject of dialogues) to express the horizontal and creative course of the dialogues. Second, we began to articulate interrelationships between the different sections and maps by adding two schemes. At the beginning of the atlas, a large timeline (Figure 5) was added showing when and by whom material was added to the different atlas sections and how this changed the course of dialogues. In a second scheme 


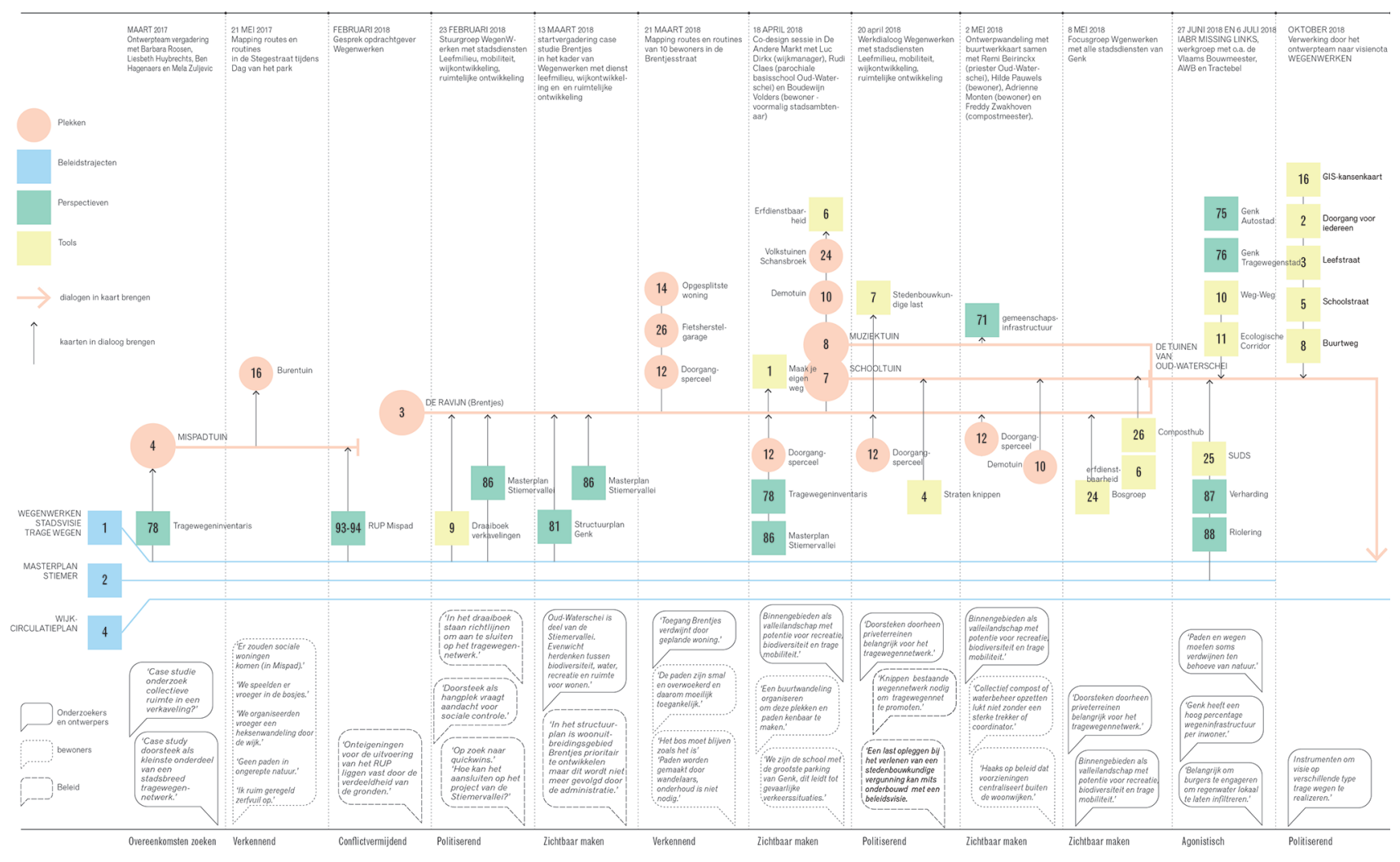

Figure 5. Timeline of the atlas-making. Source: Barbara Roosen.

(Figure 6), we started to connect the identified 'gardens' to other neighbourhood places in the atlas, also establishing links with perspectives, policies and tools that play a role in the realisation of the gardens. This scheme again created space for different types of knowledge to be discussed and to question potential synergies and conflicts between them. We realized that referencing, in the form of the two schemes, could have brought more clarity and transparency during the dialogues, not only visualizing the steps taken by different actors in the process, but also the objectives that triggered these steps.

When we left the dialectical design dialogue, the first section of the atlas told stories of 30 places on the participatory neighbourhood map, the second section included 17 dialectics between different perspectives visualised by maps produced digitally by the researchers and students, the third section discussed six policy trajectories with which the atlas went into dialogue, and the fourth section documented 26 tools that were mentioned during any of the dialogical activities.

\section{Discussion: Ethical Questioning through Atlas Techniques}

Our experience in Oud-Waterschei not only taught us how atlas techniques can help to guide a participatory planning process but also how to articulate and negotiate ethical questions that pop up during such processes to all stakeholders involved.

\subsection{The Urgency of Ethically Conscious Atlas Practices in Urban Planning}

Too often, we consider an atlas as the instrument of a professional to neutrally gather and share knowledge about a specific context, without considering its political potential. Also, if the political potential of the atlas is recognised, ethics are mostly discussed concerning the content of the participatory process and too little concerning the designerly production process of the tool-in this case, the atlas-itself (Huybrechts et al., 2016, 2018, 2019,2020 ). There is a tradition within atlas-making (see for instance Cattoor \& Perkins, 2014) which employs atlas techniques to articulate hidden local stories about the urban territory in order to "suggest possibilities, instead of limiting or constraining ways forward" (Cattoor \& Perkins, 2014, p. 176). In this article, we stretch the political potential of atlases by employing these techniques actively in negotiating ethical concerns in participatory planning processes. The openness to diverse actors as codesigners of the atlas reveals the emancipatory potential of an atlas, offering a platform to collect and confront different perspectives on the same space and taking contradictions and synergies between them as a starting point to negotiate how, with whom and for whom to plan and design our living environment. Taking the diversity and complexity of everyday reality as a starting point to enter in dialectical dialogues on ethics, rather than to dwell upon conventional programmatic themes (based upon 


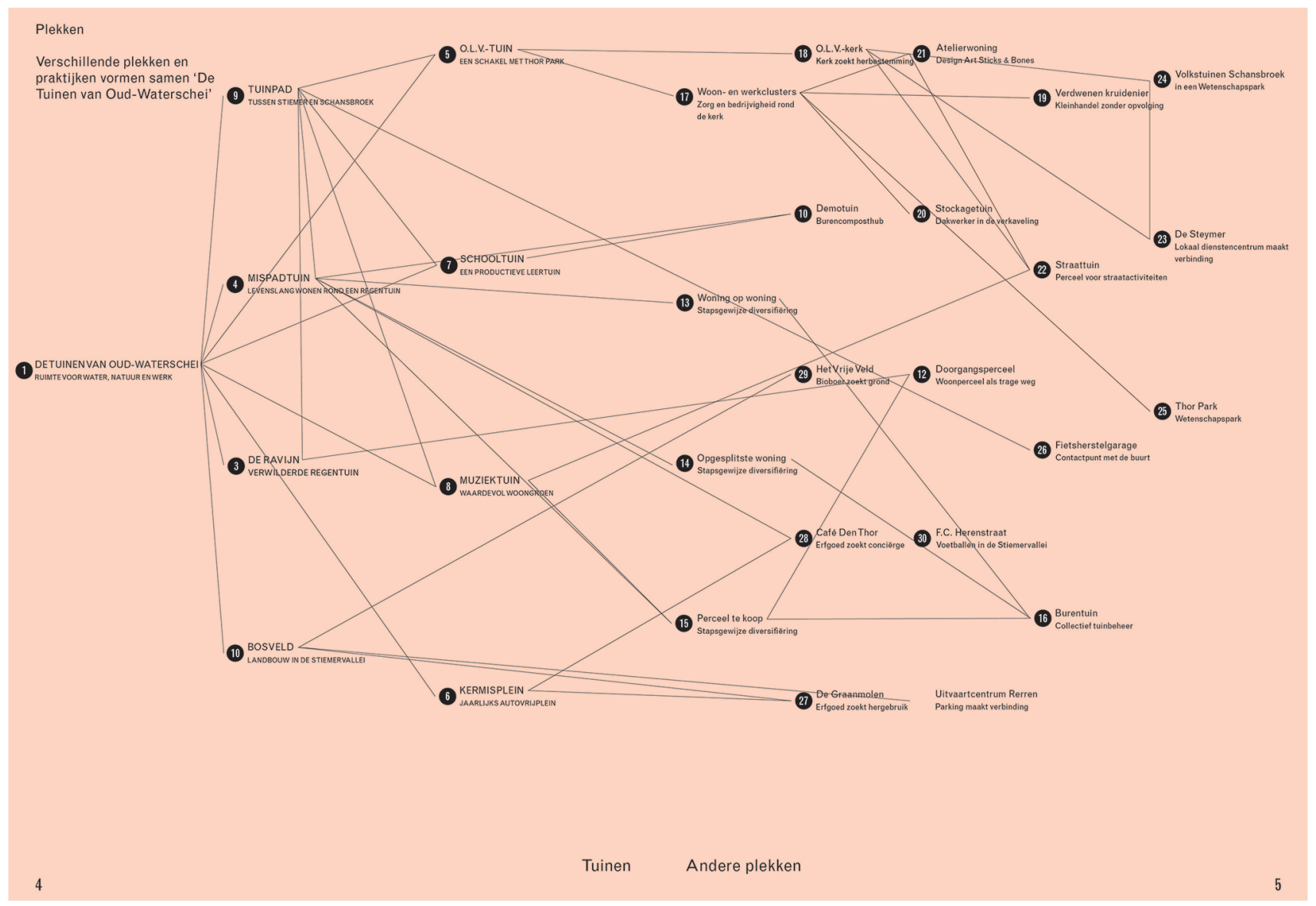

Figure 6. Scheme of relationships between different neighbourhood places in the first section 'places' of the atlas. Source: Barbara Roosen.

dominant agendas), offers a valuable contribution to the contemporary debate calling for agonistic, adaptive and discursive perspectives on planning into practice.

\subsection{How Atlas Techniques Negotiate Ethical Questions}

In this final discussion, we reflect on how the atlas techniques helped us to focus the dialectical dialogues on ethical questions. To structure this reflection, we will rely on the three ethical concepts that we discussed at the beginning of this article and which are thoroughly renegotiated in everyday urban planning practice, namely accountability, morality and authorship (see Figure 7).

Our first two techniques, structuring (Section 3.1) and making montages (Section 3.2), helped to reveal several dialectics in the dialogues among different actors: pointing at relationships within one map (between actors, practices and spaces) or between different atlas sections helped to make tensions, uncertainties, and inconsistencies between different perspectives explicit and tangible. Once revealed, these dialectics started to raise issues of accountability: who should take initiative? Who should be involved? The diversity and hands-on character of the atlas material were able to introduce a 'sense of urgency' in a context where most actors only felt accountable for their own property and stimulated each participant to imagine alternative tasks and roles for them to take up. The co-design sessions made clear what kinds of issues participants wanted to engage with, what they felt responsible for and what actions they were willing to reflect upon, or not. As such, the techniques of structuring and montage became tools for the participants to question (their own) interests, accountability and engagements, and to take that as a starting point to reflect on possible futures.

Our third and fourth techniques, namely selecting (Section 3.3) and labelling (Section 3.4), provided participants with a tool to speculate about what would be 'morally just' planning decisions. Selecting spaces, people and tools raised the question of who should be involved and what issues should be addressed. The labelling of the dialogue material helped to make clear when new perspectives or voices entered the conversation and when existing perspectives grew more or less dominant. Both techniques made it possible for participants to consciously insert other perspectives (such as the need for local life-long living options in the case study) or make new labels for places, thus offering concrete means to counterbalance the on-going dialogues. In this way, the atlas offered a design language for different forms of moral positions to be articulated and to meet. 


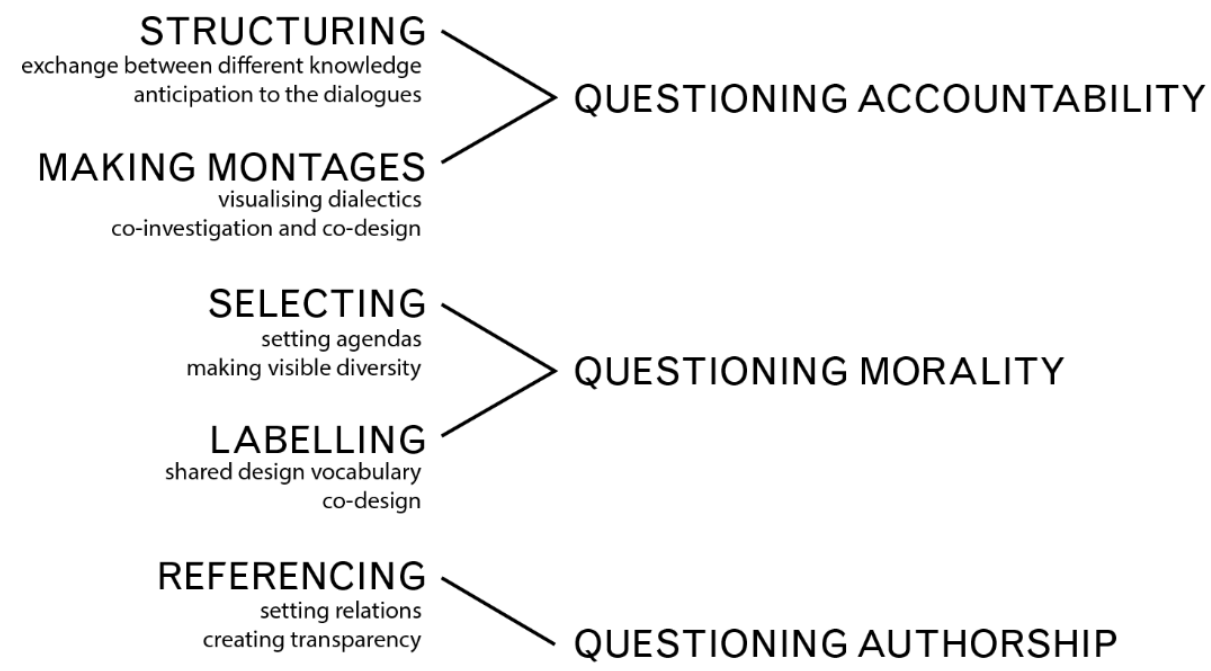

Figure 7. Overview of the interplay between atlas techniques and ethical questions. Source: Barbara Roosen.

Our fifth technique, referencing (Section 3.5), though at first neglected, later became an important tool to obtain transparency concerning lucidity of goals, context and authorship (see Barad, 2007; Suchman, 2002). In dialectical design dialogues, transparency of authorship (both regarding whom and when) is crucial in order to handle and maintain an effective dialogue between the large diversity of knowledge and actors. In our atlas, detailed referencing increased its readability, making the series of dialogues more open and accessible to new actors and enabling outsiders to step in more easily. In this way, transparency through referencing aimed at managing diversity. At the same time, we experienced that stimulating different actors to claim their role in imagining possible actions required both clarity about objectives and goals and that we did not show the planning process as a project with a clear beginning and end, but as a trajectory within a context with a long and diverse history and future.

\subsection{Mutual Learning through the Atlas}

In line with Freire (1970/2017), our case study focusing on how the design of the atlas facilitated a mutual learning process between planners, authorities and citizens that enabled articulating and addressing ethical concerns through what we called dialectical dialogues. This was stimulated by a thorough exploration of a tool common to urban planners, the atlas, which supported the destabilisation of existing viewpoints on neighbourhood spaces by confronting them with other ones through particular techniques, a dialogical process which enabled shifts in the perspectives and insights of planners, authorities and citizens involved. Particular learnings that different actors engaged in are of particular import in this final discussion.

First, the making of the atlas prompted us to adjust and enrich our design and research agenda through- out the process and made us increasingly acknowledge the authorship of other actors. The technique of referencing, which is a quite common academic practice but not often used among designers, proved very valuable in the building of the atlas. In our case, we only adopted it towards the end. Including it from the start though, would have allowed to continuously renegotiate participants' engagement and question power relations, while discussing ethics in relation to responsibilities, roles and authorship.

Second, expert participants (including, among others, policymakers) learned to appreciate the microscale dialogical activities facilitated by the detailed montage technique. The municipal administration of the city of Genk, for instance, at first was reluctant to accept our decision to focus on the neighbourhood of Oud-Waterschei. It was unclear for them what they could learn from the case except for gaining citizen support to their master plan for the adjacent Stiemer creek. However, by being part of the montage sessions of the atlas, they became interested in the stories (and dialectics) that came together during these sessions and which remained under the radar of planning policy. They started exploring ways to activate these stories in on-going policy projects and plans.

Third, inhabitants were mostly engaged through the collaborative montage and labelling techniques that enabled them to frame their own practices and agendas within a broader societal debate. They discovered how different concepts (such as sustainable urban drainage solutions) played a role in this debate and took part in relating them to their daily life experience while building a common vocabulary.

\section{Conclusion}

In this article, we explored how ethical questioning can take shape during the design research process, not only 
through discussing the content of the research but also through the conscious use and production of design-in this case, atlas-tools and techniques. We brought together insights from the fields of urban planning, mapping and participatory design to answer the question on how to more consciously raise and address ethical questions through the production of design tools in participatory planning processes.

To answer this question, we explored the role of tools in shaping dialogues in Freire's sense (1970/2017), as a way to create horizontal relations between various actors. We expanded this concept by mobilizing Harvey's $(2000,2009)$ interpretation of dialectics and how they uncover latent opportunities, to address societal concerns embedded in the everyday. This led us to suggest that tools can contribute to shaping 'dialectic design dialogues,' a new concept we created to define a multifarious learning process in which various ethical concerns are dialectically negotiated. We then particularly explored how one of the main tools used by urban planners, the atlas, can co-create such dialectical design dialogues.

In the main body of our article, we discussed how we explored this concept in a concrete case via the codesign and co-production of an atlas in a low-density residential neighbourhood. This exploration showed that our atlas techniques were indeed not neutral and can be treated (and as such, should be designed) as political and ethical devices. We discovered the many implications of these techniques' roles in initiating, materialising and interpreting dialogues, an insight which is often underestimated in planning practice. As such, our research experience may inspire other designers, planners, local authorities and communities to design and employ the potential of atlas techniques to create dialectical design dialogues that allow for real-time dealing with ethics by truly acknowledging diversity and difference proper to everyday planning contexts. We showed that conscious use of the designerly language of atlas techniques supports the exchange of knowledge and perspectives between planners, citizens and authorities through map-making and renders ethical questioning more explicit and material in the planning process. In other words, our research showed that collective action for socio-environmentally just urbanism (Harvey, 2000) can be supported by more conscious approaches to what and-as we have shownhow we map.

\section{Acknowledgments}

Our thanks to the reviewers for the critical comments which helped to improve the article, to the municipality of Genk and inhabitants of Oud-Waterschei for their essential support and participation, to the students of the urban design seminar 2018-2019 of the University of Hasselt for helping to produce the atlas and to the NGO Trage Wegen for the confidence in our participatory approach.

\section{Conflict of Interests}

The authors declare no conflict of interests.

\section{References}

Barad, K. (2007). Meeting the universe halfway: Quantum physics and the entanglement of matter and meaning. Durham, NC: Duke University Press.

Cattoor, B., \& Perkins, C. (2014). Re-cartographies of landscape: New narratives in architectural atlases. The Cartographic Journal, 51(2), 166-178.

Corner, J. (1999). The agency of mapping: Speculation, critique and invention. In D. Cosgrove (Ed.), Mappings (pp. 213-252). London: Reaktion Books.

Crampton, J. W., \& Krygier, J. (2006). An introduction to critical cartography. ACME: An International E-Journal for Critical Geographies, 4(1), 11-33.

Freire, P. (2017). Pedagogy of the oppressed. London: Penguin Classics. (Original work published 1970)

Harvey, D. (2000). Spaces of hope. Berkeley, CA: University of California Press.

Harvey, D. (2009). Cosmopolitanism and the geographies of freedom. New York, NY: Columbia University Press.

Healey, P. (1997). Collaborative planning: Shaping places in fragmented societies. Vancouver: UBC Press.

Hillier, J. (2007). Stretching beyond the horizon: A multiplanar theory of spatial planning and governance. Aldershot: Ashgate.

Hillier, J. (2011). Strategic navigation across multiple planes: Towards a Deleusean-inspired methodology for strategic spatial planning. The Town Planning Review, 82(5), 503-527.

Huybrechts, L., Dreessen, K., \& Hagenaars, B. (2018). Building capabilities through democratic dialogues in the traces of coal project in Belgium. Design Issues, 34(2), 80-95.

Huybrechts, L., Dreessen, K., Schepers, S., \& Calderon Salazar, P. (2016). Democratic dialogues that make cities 'work.' Strategic Design Research Journal, 9(2), 100-111.

Huybrechts, L., Roosen, B., Verbakel, W., \& Schreurs, J. (2019). Ruimtelijke capaciteitsopbouw doorheen democratische dialoog: Een inzicht in een participatief ontwerpproces van een alternatieve toekomst voor het Genkse Kolenspoor [Spatial capacity building through democratic dialogue: An insight into a participatory design process of an alternative future for the Genk coal track]. In A. Kuhk, H. Heynen, L. Huybrechts, F. Moulaert, \& J. Schreurs (Eds.), Participatiegolven: Dialogen over ruimte, planning en ontwerp in Vlaanderen en Brussel [Participation waves: Dialogues about space, planning and design in Flanders and Brussels] (pp. 167-190). Leuven: Leuven University Press.

Huybrechts, L., Teli, M., Zuljevic, M., \& Bettega, M. (2020). Visions that change: Articulating the politics of participatory design. CoDesign, 16(1), 3-16. 
Kelly, J. (2018). Towards ethical principles for participatory design practice. CoDesign, 15(4), 329-344.

Loftus, A. (2012). Everyday environmentalism: Creating an urban political ecology. Minneapolis, MN: University of Minnesota Press.

Merrifield, A. (2002). Dialectical urbanism: Social struggles in the capitalist city. New York, NY: Monthly Review Press.

Metzger, J., Allmendinger, P., \& Oosterlynck, S. (2014). Planning against the political: Democratic deficits in European territorial governance. New York, NY: Routledge.

Mostafavi, M. (2017). Ethics of the urban: The city and the spaces of the political. Zurich: Lars Müller Publishers.

Nolf, C. (2013). Challenges of upstream water management and the spatial structuring of the nebulous city. (Unpublished doctoral dissertation). KU Leuven and Hasselt University, Belgium.

Parker, B. (2006). Constructing community through maps? Power and praxis in community mapping. The Professional Geographer, 58(4), 470-484.

Rule, P. (2011). Bakhtin and Freire: Dialogue, dialectic and boundary learning. Educational Philosophy and Theory, 43(9), 924-942.

Salazar, P., Zuljevic, M., \& Huybrechts, L. (2018). Southern manners in northern lands: Design interventions for autonomía. Strategic Design Research Journal, 11(2), 104-114.

Serpa, B., Portele, I., Costard, M., \& Silva, S. (2020). Political-pedagogical contributions to participatory design from Paulo Freire. In C. Del Gaudio (Ed.), 16th participatory design conference 2020: Participation(s) otherwise (pp. 170-174). New York, NY: Asso- ciation for Computing Machinery.

Söderström, O. (1996). Paper cities: Visual thinking in urban planning. Cultural Geographies, 3(3), 249-281.

Solnit, R. (2010). Infinite city: A San Francisco atlas. Los Angeles, CA: University of California Press.

Spiel, K., Brulé, E., Frauenberger, C., Bailley, B., \& Fitzpatrick, G. (2020). In the details: The micro-ethics of negotiations and in-situ judgements in participatory design with marginalised children. CoDesign, 16(1), 45-65.

Suchman, L. (2002). Located accountabilities in technology production. Scandinavian Journal of Information Systems, 14(2), 91-105.

Swyngedouw, E. (2005). Governance innovation and the citizen: The Janus-face of governance-beyond-thestate. Urban Studies, 42(11), 1991-2006.

Tice, J., \& Steiner, E. (n.d.). La nuovo topografia di Roma Comasco [The new topography of Roma Comasco]. The Nolli Map Website. Retrieved from http://nolli. uoregon.edu/default.asp

Van den Broeck, P. (2019). Mythes over participatie in wijkontwikkeling: Het Antwerpse Schipperskwartier als case [Myths of participation in neighbourhood development: The case of the Antwerp red light district]. In A. Kuhk, H. Heynen, L. Huybrechts, F. Moulaert, \& J. Schreurs (Eds.), Participatiegolven: Dialogen over ruimte, planning en ontwerp in Vlaanderen en Brussel [Participation waves: Dialogues about space, planning and design in Flanders and Brussels] (pp. 73-98). Leuven: Leuven University Press.

Wood, D. (1987). Pleasure in the idea: The atlas as narrative form. Cartographica, 24(1), 24-46.

\section{About the Authors}

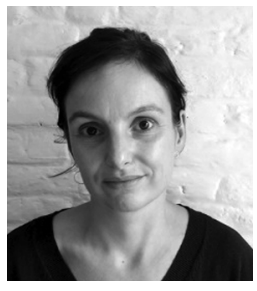

Barbara Roosen is an Architect, Teaching Assistant and PhD Candidate at the Faculty of Architecture and Arts, University of Hasselt, Belgium. In her PhD research, she investigates relationships between dialogues and mapping, focussing on durable transformation processes in the specific context of Flemish low-density residential neighbourhoods. As part of the research Cluster Spatial Capacity Building, she is involved in several participatory research projects with particular focus on collectivity in suburban work and living environments.

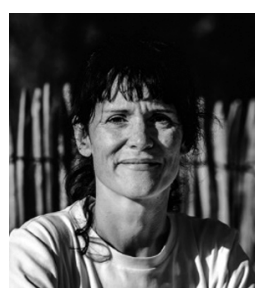

Liesbeth Huybrechts is an Associate Professor and works in the areas of participatory design, design anthropology and spatial transformation processes in the research group Arck, University of Hasselt. She has developed a research interest in collectivity and commons in city and region-making which she explores in several research and educational projects. This had led for instance to the creation of the Living Lab De Andere Markt, a space that explores the future of work in the city.

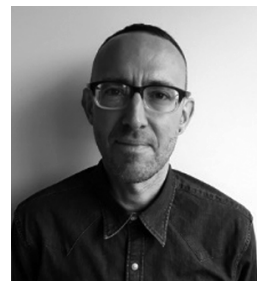

Oswald Devisch is an Associate Professor in Urban Design at the Faculty of Architecture and Arts, University of Hasselt, Belgium. He is the Coordinator of the research cluster Spatial Capacity Building exploring themes such as collective learning, casual participation, autonomous transformation processes and the gamification of participation. 


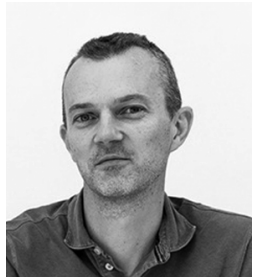

Pieter Van den Broeck is a Professor of Spatial Planning and Sustainable Development in the Department of Architecture at KU Leuven. From a critical institutionalist perspective and a methodological interest in transdisciplinary action research, he engages in research on spatial planning, territorial development and social innovation, governance of socio-ecological systems, and land dynamics and commons. He is the Coordinator of the Research Unit Planning and Development and the International Module in Spatial Development Planning. 